\title{
Exploring Student Computational Practices in Solving Complex Engineering Design Problems
}

\section{Mrs. Oluwatosin Alabi, Purdue University, West Lafayette}

Oluwatosin (Tosin) Alabi is a graduate researcher in Computer and Information Technology. Currently, she is conducting research in High Performance Computing (HPC) and Data Analytics. Specifically, her research is focused on the use of parallel computational tools in supporting big data problem solving in bioscience and information technology.

She holds a Masters in Computer and Information Technology, where her thesis focus on the role of computational tools and representations in engineering education. And also holds a B.E. degree in Electrical Engineering from The City College of New York where she worked as a research assistant in the are of Remote Sensing and Atmospheric Science.

Tosin is also a graduate of the General Electric Edison Engineering Leadership Development Program (EEDP). During her time at General Electric (GE) her roles included working as an Electronic Component Quality Engineer for GE Switchgear Systems.

Her research interest include: High Performance Computing, Data Analytics, and STEM Education

\section{Dr. Alejandra J. Magana, Purdue University, West Lafayette}

Dr. R. Edwin Garcia, Purdue University, West Lafayette 


\title{
Exploring Student Computational Practices in Solving Complex Engineering Design Problems
}

\begin{abstract}
Computational tools are becoming more useful pedagogical tools because of their ability to create and display multiple representational forms, often interactively, and as a function of time. Specifically, representational artifacts such as graphs, visual models, and simulations of physical or non-physical phenomena can serve as tools in guiding inquiry and constructing solutions in engineering design. However, there is a limited amount of research that describes the computational practices of engineering students. In particular, there is a need to investigate the way engineering students use computational tools for developing solutions to complex design problems beyond the first year of engineering. This study investigates graduate students' computational practices that inform their problem-solving processes to accomplish a design task. In this paper we define computational practices as a system of activities carried out to create symbolic representations. These representations refer to simplifications of systems or artifacts that delete, maintain and distort aspects of a phenomenon in order to support scientific inquiry and design activity. The research question from this study is: How do graduate students engage modeling and computational practices towards problem solving in a material science rechargeable battery design course?

A theoretical framework based on Lev Vygostky's Activity theory was used for understanding and describing the role of computational resources used by lower level graduate students for problem solving. In particular, the study investigated two groups of participants that were tasked to utilize different computational resources: analytical or computational. A qualitative analysis was used to perform an in-depth examination of students' solutions consisting of three elements; the subject, mediating tools and the task objectives. The results of this study will be beneficial in expanding the current work in investigating the role of representations for conceptual change in engineering and provide insights into how students process knowledge when provided with simulation tools and computational methods for solving design problems.
\end{abstract}




\section{Introduction}

Computer modeling and simulation are emergent pedagogical tools implemented for teaching concepts in science, technology, engineering and mathematics (STEM) education. One pedagogical objective for integrating computer modeling and simulation within learning environments is to help students develop deeper understanding of a physical phenomenon through visualization and dynamic interaction of abstract concepts or complex systems. When modeling and interacting with numerical simulation, a student must be able to analyze, synthesize, and evaluate relevant domain knowledge in order to create and investigate the system's phenomena ${ }^{1,2}$. Currently, there is a growing body of research that provides insights for researchers and instructors regarding (a) how students construct conceptual meaning through the use of simulation and modeling tools ${ }^{3,4}$, (b) what are the effects of students' prior learning and misconceptions on their modeling process ${ }^{3,5,6}$, and (c) what are pedagogical approaches that explore the role of computer simulations for the design of students' learning environments ${ }^{7,8}$. However, there is a limited amount of research that describes engineering students' computational practices in the context of complex problem solving. In particular, there is a need to investigate how engineering students employ computational tools in developing their solutions to complex design problems beyond the first year of engineering. In this paper, we define computational practices as a system of activities carried out to create symbolic representations. These representations refer to simplifications of systems or artifacts that delete, maintain and distort aspects of a phenomenon in order to support scientific inquiry and design activity ${ }^{9}$. The research question in this particular study was:

How do graduate students engage modeling and computational practices towards problem solving in a material science rechargeable battery design course?

The goal of this paper is to describe students' computational practices for processing domainrelevant knowledge and their strategies for formulating solutions. In addition, the differences in students' problem solving processes using hand-written and coded methods of computing are highlighted and discussed. The results of this study will be beneficial in expanding the current work that investigates the role of computing and representational systems in supporting learning in engineering education and will provide insights into how students process knowledge when provided with simulation tools and computational methods for solving design problems.

\section{Theoretical Framework}

Activity theory was used as the theoretical framework for this study. Mediating artifacts in activity theory, like computer models and simulations, function to help individuals accomplish intended goals (the outcome) and help inform the actions an individual employs when completing a specific task ${ }^{10}$. Lev Vygostky's developed the Activity Theory framework, which consists of three main elements; the subject, the mediating tools and the task objective or outcome. In general Vygotsky's theory highlighted a relationship between social interactions and objects that facilitate individuals' conceptual development. Vygostky asserted that learning proceeds development and occurs through the mediation of tools (i.e., language and objects) and other agents in the environment (i.e., a teacher or more knowledgeable other). In this study, we 
focus on the role of analytical modeling and computer tools in informing students' conceptual development when solving complex problems in material science and engineering.

In order to study the role of computer technology and its relationship with students' problem solving activities, we adapted the four key principles of Lev Vygostky Activity Theory proposed in Nardi's edited book surveying the issues of activity theory and human-computer interaction ${ }^{11}$. The first principle is that learning and problem solving are object-oriented activities. This principle highlights the goal-oriented nature of human activity in directing and transforming a problem space into specific outcomes with the help of external and internal mediating tools (e.g., language, instruments and artifacts) ${ }^{12}$. The second principle, mediation, which refers to the tools (both physical and psychological) that individuals use as resources to help them mediate their actions and learning while participating in an activity. Mediation is considered optimized when the learner is in the zone of proximal development (ZPD) ${ }^{13}$. ZPD is the appropriate learning gap between a novices' current developmental state and a higher level of knowledge that will not be too challenging or too easy for the learner ${ }^{13}$. The third principle states that context in which an actitivity is performed influences the nature of the development process. Lastly, the fourth key principle of activity theory states: "mental processes are derived from external actions through the course of internalization" ${ }^{14}$. This process of internalization relates to the process of acquiring new knowledge guided by a person's ability to construct their mental processes through meaningful participation in real-world experiences. This internalization of knowledge also informs the future operations that the subject will employ in future learning or problem space activity.

In this study, we investigated students' solution outcomes as the artifacts they produced when solving a design problem related to modeling a rechargeable battery using analytical and computational modeling tools. The focus of this study was to examine the computational solutions of upper level engineering students produced in modeling a graded porous electrode used in a rechargeable battery system. This activity system is depicted in figure one.

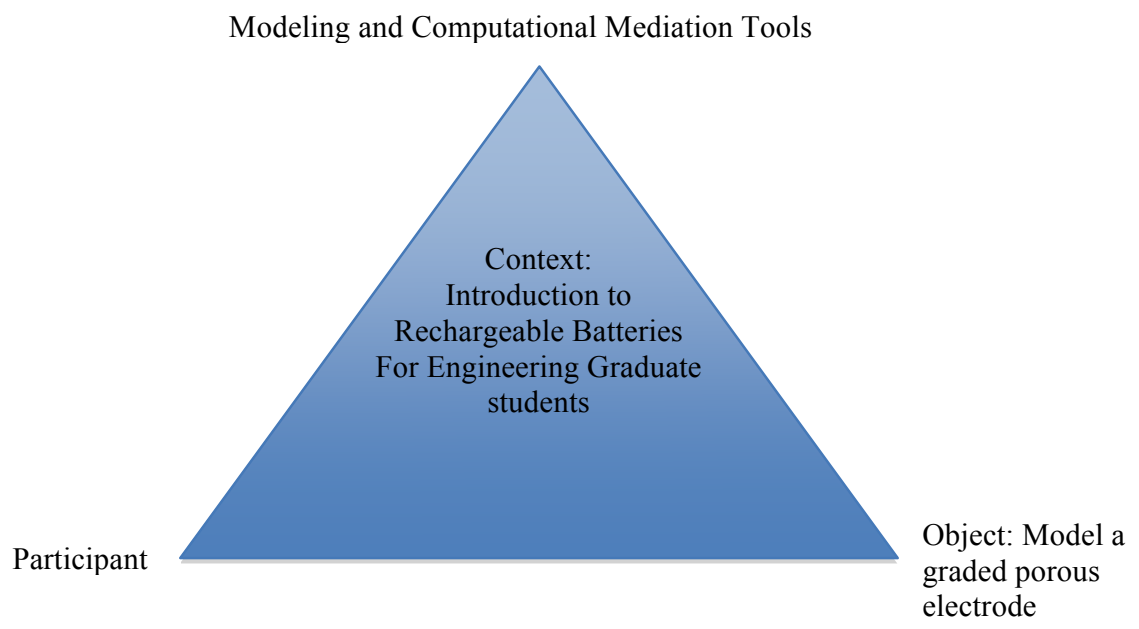

Figure 1. Vygostky's activity theory model for this study. 


\section{Research Design and Methods}

\section{Instructional Context}

The course entitled "Introduction to Rechargeable Batteries" is an elective course for upper level undergraduate and graduate students interested in developing an understanding on the materials science of rechargeable batteries. This course included an introduction to basic electrochemistry, principles of electrochemical devices, and electroactive materials as used in rechargeable battery systems. The instructional goal for the course was to provide students expertise regarding the fundamental analytical and computational modeling techniques used by the battery industry through leaning the theoretical and practical aspects of battery fabrication. The instructional team designed this course to build students' conceptual understanding by integrating the use visualization and graphical artifacts, like the ones depicted in figure two, and engaging the students in the use of modeling and computational analysis to complete class projects and homework assignments.

In addition, the instructor focused on teaching students how to model and analyze battery systems using analytical and computational techniques used by practitioners and research experts in battery systems design. The computation tool used in the course was the Virtual Kinetics of Materials Laboratory (VKML). The VKML tool is an open source online computing tool that performs mulitiphysical equilibrium and kinetic calculations of material properties ${ }^{15,16}$. This tool was designed as an open source scripting language by a materials science research team to enable the user to focus on rapid model development and visualization of results, and not programming ${ }^{15}$. It has several built-in GUIs and Python scripts that students can execute and modify in modeling the material behavior characteristics of a rechargeable battery system. We classify the VKML tool as a computational simulation tool; that is VKML is a research simulation tool developed for experts that was then integrated into engineering and science courses at the university level ${ }^{17}$.
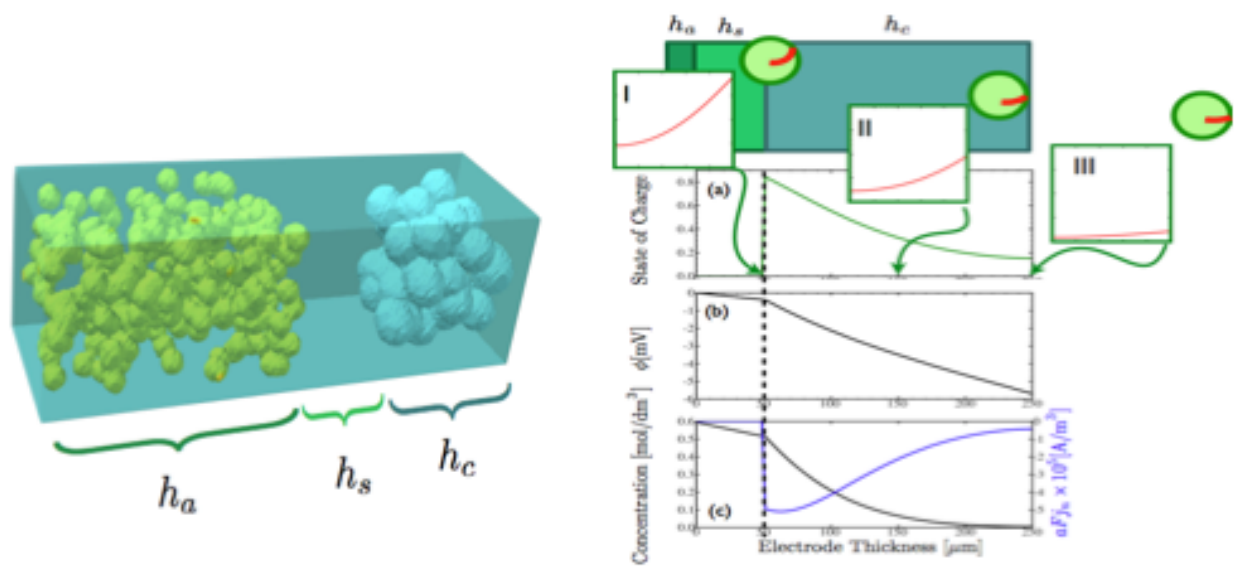

Figure 2. Visual artifacts used to support students' conceptual understanding. ${ }^{18}$ 


\section{Participants}

The participants consisted of first and second year graduate students from a top ranking midwestern engineering program. To protect the identity of the ten participants, demographic information was not disclosed to the researchers. The participants were grouped into two categories based on the two different homework assignments (self-selected by each participant). The differences between the two homework assignments were on the modeling or computational approaches they were required to use. The two groups and their members' pseudonyms are listed on table one. Table 1 also describes the activity systems students used to approach the design task.

\section{Data Collection and Data Analysis Methods}

In order to gain insight into students' modeling and computational practices, the research design included the use of two problem-solving activities that involved the use of different mediating tools. Each group had a task to accomplish with a similar objective. The objective consisted of modeling and analyzing a graded porous electrode to be used as part of a rechargeable battery system. For group one assignment students employed analytical procedures and provided detailed hand written calculations for solving their homework assignment. Participants from group two were tasked to use The Virtual Kinetics of Materials Laboratory (VKML) tool to develop their computational model and support their analysis as part of the problem solving activity. The submitted individual course assignments served as the raw data used to examine students' modeling and computational practices.

Table 1. Activity system used to explore students modeling and computational practices.

\begin{tabular}{|c|c|c|}
\hline Activity element & Group One & Group Two \\
\hline $\begin{array}{c}\text { Participants and } \\
\text { Pseudonyms }\end{array}$ & $\begin{array}{c}\text { Five participants: Cade, Kelab, Scott, } \\
\text { Troy and Leon. }\end{array}$ & $\begin{array}{c}\text { Five participants: Jack, Sean, Drew, } \\
\text { Rick, and Tony. }\end{array}$ \\
\hline \multirow{3}{*}{ Mediating Tool/Artifacts } & $\begin{array}{c}\text { Mathematical, numerical and material } \\
\text { science modeling principles/concepts. } \\
\text { Students were allowed to use any tool, } \\
\text { hand calculations and other tools to } \\
\text { support their operations for modeling } \\
\text { and system analysis }\end{array}$ & $\begin{array}{c}\text { The Virtual Kinetics of Materials } \\
\text { their model and support their analysis }\end{array}$ \\
& $\begin{array}{c}\text { Develop an analytical model and } \\
\text { Task Objective }\end{array}$ & $\begin{array}{c}\text { Develop a computational model and } \\
\text { analysis of a graded porous electrode. }\end{array}$ \\
\hline
\end{tabular}

The assignment questions were developed by the instructional team to help engage the students in all the components of problem solving defined by Polya process for solving mathematical based problems ${ }^{19}$. Polya's four step model for problems solving with mathematical methods includes: (1) Representation of the problem, (2) Goal setting and planning, (3) Execution of the plan and (4) Evaluation of the solution. These steps were mapped to the assignment questions for each group as shown in table two. These mappings helped examine and highlight students' 
documented goal-oriented tasks towards developing their solutions to the problem assignment. Students' responses were investigated using open-coding analysis to identify the patterns and themes embedded in student responses ${ }^{20}$. In particular, an inductive analysis was conducted using the framework from activity theory to investigate the actions, operations and conceptual process that upper level engineering students employed in modeling a graded porous electrode used in a rechargeable battery system. As themes emerged, each was examined to identify similarities and differences in the set of actions and operations taken by the collection of all participants in each group. In addition, we looked for insight into understanding the relationships of theses actions and operations to the activity outcomes and how these outcomes were relevant in understanding students' use of computation tools and conceptual understanding.

Table 2. Activity Objectives for each group mapped into Polya's Model for Problem Solving ${ }^{19}$

\begin{tabular}{|c|c|c|}
\hline $\begin{array}{l}\text { Polya's Problem } \\
\text { Solving } \\
\text { Objectives }\end{array}$ & Group One Assignment & Group Two Assignment \\
\hline $\begin{array}{l}\text { Represent the } \\
\text { problem }\end{array}$ & $\begin{array}{l}\text { 1. For the porous graded electrode with } \\
\text { given gradient develop an expression for } \\
\text { the reaction zone. }\end{array}$ & $\begin{array}{l}\text { 1. Extend the proved script to describe the } \\
\text { porous graded electrode with given } \\
\text { gradient. Make the appropriate } \\
\text { substitutions for the reaction zone and } \\
\text { baseline porosity. }\end{array}$ \\
\hline $\begin{array}{l}\text { Goal setting and } \\
\text { Planning }\end{array}$ & $\begin{array}{l}\text { 2. Find conditions for which the reaction } \\
\text { zone will be positive and real. How will } \\
\text { this result impose a constraint on the } \\
\text { porosity gradient? } \\
3 \& 4 \text {. Find an expression for the } \\
\text { discharge time given the conditions of } \\
\text { the porosity gradient, a. where a }>0 \\
\text { (Q3), positive and } a<0 \text { (Q4), negative. }\end{array}$ & $\begin{array}{l}\text { 2. Given your developed model propose a } \\
\text { battery microstructure: porosity gradient } \\
(\mathrm{a}) \text {, baseline porosity }\left(\varepsilon_{\mathrm{o}}\right) \text {, electrode } \\
\text { thickness }\left(\mathrm{h}_{\mathrm{c}}\right) \text { that optimizes the battery } \\
\text { microstructure for a LinMn2O4 based } \\
\text { system. }\end{array}$ \\
\hline Execute the Plan & $\begin{array}{l}\text { 5. For both types of porosity gradient } \\
\text { electrodes, a is positive or negative, } \\
\text { which will allow for longer discharge } \\
\text { time on the electrode? } \\
\text { 6. For the LiMn2O4-based system } \\
\text { propose: a porosity gradient }(\mathrm{a}) \text {, baseline } \\
\text { porosity }\left(\varepsilon_{\mathrm{o}}\right) \text {, and electrode thickness } \\
\left(\mathrm{h}_{\mathrm{c}}\right) \text { that optimize the battery } \\
\text { microstructure for a LinMn } 2 \mathrm{O} 4 \text { based } \\
\text { system. }\end{array}$ & $\begin{array}{l}3 \& 4 \text {. Using the developed model find the } \\
\text { porosity gradient the minimizes/ } \\
\text { maximizes the discharge time given the } \\
\text { conditions of the porosity gradient, a. } \\
\text { where } a>0(\mathrm{Q} 3) \text {, positive and } \mathrm{a}<0(\mathrm{Q} 4) \text {, } \\
\text { negative. } \\
5 \text {. For both types of porosity gradient } \\
\text { electrodes, a positive and negative, which } \\
\text { will allow for longer discharge time on the } \\
\text { electrode? }\end{array}$ \\
\hline $\begin{array}{l}\text { Evaluate the } \\
\text { solution }\end{array}$ & $\begin{array}{l}\text { 7. How would your results change if you } \\
\text { instead use a battery with constant } \\
\text { porosity, } \varepsilon_{0} \text { ? } \\
\text { 8. Considering the results obtained in } \\
\text { questions } 6 \& 7 \text {, comment on the } \\
\text { advantages and disadvantages of a } \\
\text { graded porous electrode battery. }\end{array}$ & $\begin{array}{l}\text { 6. How would your results change if you } \\
\text { instead use a battery with constant } \\
\text { porosity, } \varepsilon_{0} \text { ? } \\
\text { 7. Considering the results obtained in } \\
\text { questions } 2 \& 6 \text {, comment on the } \\
\text { advantages and disadvantages of a graded } \\
\text { porous electrode battery. }\end{array}$ \\
\hline
\end{tabular}




\section{Results and Discussion}

The results are discussed in two sections. The first section summarizes the inductive analysis from the individuals that completed the assignment where students used analytical hand written calculations (i.e. group one participants). The second section summarizes the themes and patterns from the individuals who were tasked to use the VKML tool as part of their process for completing the assignment (i.e. group two participants). The inductive analysis of the data in both groups was aimed at understanding how graduate students implemented analytical and modeling and computational practices towards problem solving and conceptual understanding of course material.

\section{Group One: Developing an analytical model of a graded porous electrode}

Conceptualizing algebraic and symbolic forms

Students' ability to conceptualize the algebraic and symbolic forms supported the development of their mathematical models for representing the problem and planning out the problem solving process. The participants in this study were tasked to solve a problem that would require the use of the language and principles from the material science and engineering domain that were communicated using algebraic and symbolic forms. As students worked through the problem, they provided some descriptions relating variables (symbols) expressing the physical properties. These relationships were useful in formulating their analysis and executing their actions within their problem solving activity.

For example, in defining the equation that would model the reaction zone, Scott and Troy provided their conceptualization of the relationship displacement variable, $\mathrm{x}$, and the reaction zone variable $\mathrm{x}_{\mathrm{r}}$ in the form of written summaries. Scott's response is depicted in Figure 3 below:

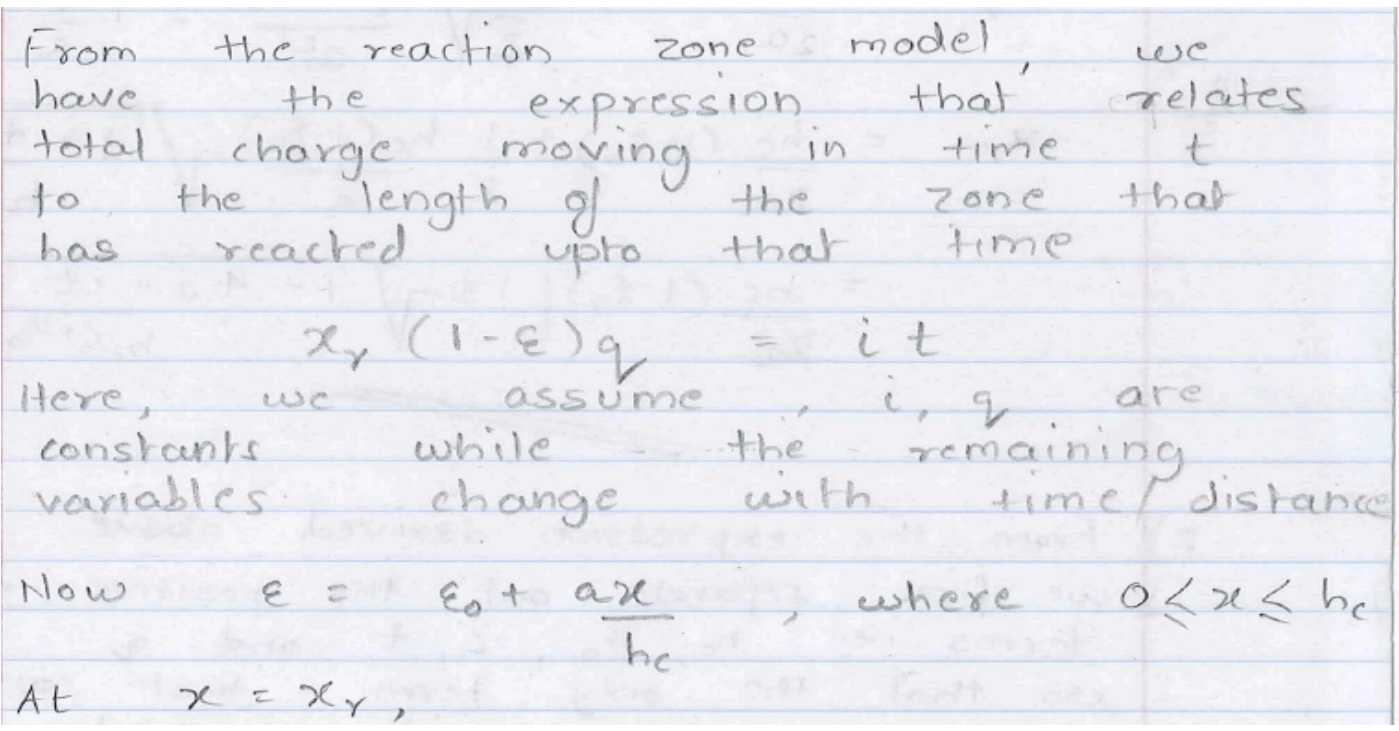

Figure 3. Scott's conceptualization for modeling the reaction zone, $x_{r}$. 
Mathematical and Graphical Transformations

Students' mathematical transformations were used to help them simplify the conditional relationships among system parameters when they were taking actions related to setting the task goals and performing solution analysis. Leon, Cade, Kelab and Scott were able to use the quadratic formula to determine an expression for the reaction zone and identified an appropriate relationship that simplified their mathematical equation used to calculate the discharge time. These students also noted that by the time the system completely discharged, the electrode thickness would be equal to the length of the reaction zone at time $t_{d}$. This information and other such conceptualizations allowed students to transform the original equation for determining the expression for discharge time.

Furthermore, students did not only rely on mathematical transformations to simplify their analysis and examine relationships between two variables at a time. Some students (Scott and Cade) also created their plots using the approximations by hand, while others created their plots using computing programs (Leon and Kelab). In these cases, the graphical transformations were also part of students' operations for executing or evaluating their solutions.

Students' uses of a Symbolic Computing Tool

In this activity students were asked to perform an analytical model where a majority of the calculations could be completed by hand written evaluation. However, two students, Leon and Kelab, chose to use mathematical computing tools to solve the problem. Kelab used WolframAlpha $^{\mathrm{TM}}$ and Leon used WolframMathematica ${ }^{\mathrm{TM}}$ to model and analyze their solutions. These Wolfram ${ }^{\mathrm{TM}}$ software tools can be described as symbolic numerical computing tools. The one used by Leon allowed him to enter the equations and run computations dynamically and interactively, with out specifying the numerical techniques. That is, he only specified the mathematical operations in algebraic form. Leon submitted his program as part of his assignment, which included all graphical plots. In the case of Kelab, he referenced the results provided by WolframAlpha ${ }^{\mathrm{TM}}$ in computing his analysis. However, his program was not attached to the assignment, suggesting the tool functioned more as calculation and graphing tool. In both cases the use of these computing tools helped students to compute their calculations using the analytical models related to the modeling of rechargeable battery systems.

\section{Group Two: Developing a computational model of a graded porous electrode}

Conceptualizing symbolic parameters

Students' conceptualizations of the system variables we articulated by the comments they added as part of their modification to the VKML template program. A group of students incorporated comments that provided descriptions of the symbolic parameters that helped highlight attributes of system behavior characteristics (Tony, Drew, and Rick). This is highlighted in Figure 4 using an excerpt from Rick's VKML code. Other students related their comments to describe the procedural actions they were executing in the line of code, such as (a) initialization of parameters and variables and (b) making notes regarding the actions a particular line of code should accomplish (Sean and Jack). 


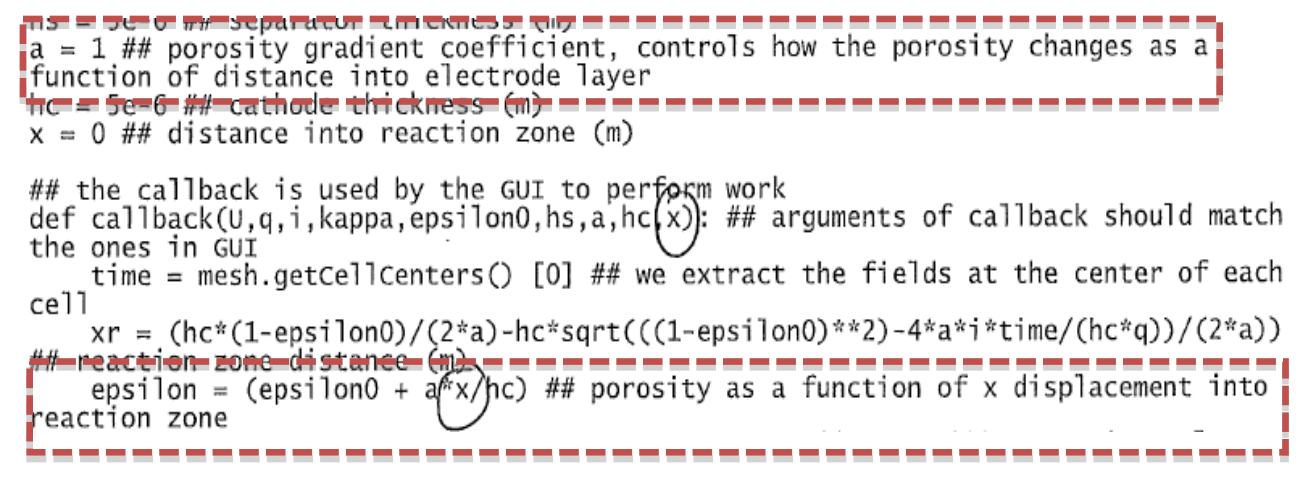

Figure 4. Ricks' comments conceptualizing using system behavior characteristics

These comments provided insights into the operations and mental process students utilized in modifying their computer algorithm using the VKLM tool. When modifying the simulation code to update the parameter inputs and response abstractions, some students primarily conceptualized their code in terms of actions they were performing in their scripts. These comments suggest procedural skills students employed in decomposing their algorithm and identifying the physical characteristics for building their computation models using the VKML tool.

Formulating Function Abstractions

The formulation of the functions employed to model the system under investigation were supported by the students' (1) ability to make the appropriate substitution and (2) understandings of how to code mathematical abstractions using a graphical interface. Students in the computational modeling group were provided with the mathematical expressions that would be helpful in formulating function abstractions of the porous graded electrode. Although not all the functional algorithms were error-free, some students were able to create an executable code (Drew, Jack, Sean). For instance, Sean's code contained an error and he was unable to execute his program for positive values of the porosity gradient. This error occurred because the input parameters he programmed for the graphical interface restricted the input range to negative values. Although he noted that the run-time error could be related to the range limit, there was no evidence to suggest that he was aware on how to fix the issue in his algorithm.

Furthermore, when formulating functional abstractions to complete their algorithm, some students (Rick, Tony) struggled. In particular, students faced challenges in determining the relationship among system parameters (e.g., dependent vs. independent). Students also struggled in defining the functions for programming the equation that modeled the reaction zone displacement, $\mathrm{x}_{\mathrm{r}}$, and electrode porosity, epsilon that were needed to investigate the behavior of graded electrode system. In addition, because the dependent and independent variables were not correctly identified in formulating their functions, the algorithm used to set up for the graphical interface was completed incorrectly.

Deductive Inferences Using Graphical Artifacts and Analytical Methods The majority of students' evaluations and interpretations were related to their deductive analysis using graphical artifacts that were created using their modified VKML computer program (Drew, Jack, Sean). This was highlighted by students' uses of screen shots of their responses depicting plots and graphical interfaces as part of their response to the questions in the problem activity. In 
addition, when their artifacts were not included in their response, students' analyses were based on their observations of the output plots generated by the VKML simulation. An example is provided below from Jack's reply to question seven, related to the evaluation of advantages of a graded porous electrode battery:

"If we compare the results from the constant porosity to the one with a porosity gradient you see that the maximum time the battery is discharged is bigger for the porosity gradient disregarding if it is a positive or negative gradient.

Compared to the negative gradient, the curve goes down faster in the end for it goes faster in the beginning ..."

Although most of the students were able to evaluate and execute their solutions using the graphical interface, one student, Rick, used analytical expressions to (a) represent the problem, (b) execute his model, and (c) evaluate the system's behavior. Given that the program was not able to run and provide a graphical interface for him to perform his analysis, he was still able to use analytical methods similar to those in the first group to complete the problem solving activity. In Rick's response to question seven he refers to the results from his analytical mathematical calculations.

"When looking at the results, graded electrodes have longer discharge times, especially the ones with a decreasing linear gradient for porosity. This is an obvious advantage of the graded electrodes..."

\section{Conclusion}

Engineering problem solving can be described as a non-uniform task in which the problem definition and the tools employed can influence the mental models (internal schema) an individual creates to process solutions ${ }^{21,22}$. In this study we examined analytical, modeling and computational processes of graduate engineering students' problem solving activities when using diverse methods and simulation tools. Using the activity theory framework, themes were identified to describe patterns in students' actions, operations and mental processes for developing their models and conducting their analysis of a porous graded electrode used in a battery system. Some of these findings included the following:

1. Students' conceptualizations of domain knowledge can help support their modeling and analysis process

2. Students' ability to perform mathematical transformations and functional abstractions (procedural knowledge) may relate to their conceptual understandings of the system parameters and the relationships those parameters have to one another

3. Students' use of computational tools and methods may relate to their preferences or level of expertise with a particular tool or method.

These finding in particular indicate that the combination of domain and procedural knowledge are important factors to consider when developing pedagogy that involves the use of computational resources. Specifically, the results of this study provide some evidence that students' processes for representing problems and applying computational methods are related to an individual's conceptualization of the domain knowledge characterizing the system parameters and their relationships. Chi, Feltovich and Glaser ${ }^{5}$ defined problem representation as "a cognitive structure 
corresponding to a problem, constructed by a solver on the basis of his or her domain related knowledge and it's organization (p.22)." In this definition of problem representation, the emphasis is placed on the learner's conceptualization of knowledge as a key component in developing problem solutions. This abstraction has been observed to be influential in helping experts cue the associated information and interactions from a knowledge domain needed to solve a particular type of problem ${ }^{5}$. In our study, the participants used their conceptualizations of the problem by noting the attributes of the symbols and equations employed in developing their model of the graded electrode. For the group tasked to use an analytical approach, it was particularly important that they also conceptualized the relationships and conditions that influence the reaction zone and electrode gradient. The second group that used the VKML tool also needed to conceptualize the parameter relationships to a functional model of the system in terms of independent input variables and dependent output parameters. Overall, for this study, participants' ability to conceptualize the problem and its features (i.e. domain knowledge) influenced the procedures they employed for problem solving.

In addition, our finding have helped provide a framework to help researchers in engineering education explore how the combination of domain and procedural knowledge can most effectively be supported as students work to solve problems using computational tools. In particular this study highlighted some items that could be useful in informing a future study regarding the use of computational resources for graduate students in engineering. These can include students' ability to perform mathematical transformations and develop functional abstractions; and their preferences or experiences in using dynamic symbolic numerical computational tools. By having students solve a problem not using the course computational tools, students were able make their problem solving processes and strategies more explicit. But these insights were limited to what students recorded as part of their solution. For example, learning about the additional resources students used that were taught as part of the course provided insights regarding the types of computational tools that students employed for solving problems in engineering. However, the symbolic numerical computing tools used by participants did not allow them to comment their code or explain how the results were applied; thus not allowing for insights into how the results of the tool were fully employed as part of students' problem solving processes.

The limitation of this study includes the small sample size and the use of students' documents without having access to recorded interview data. However, an exploratory study like this provides evidence of students' processes for using computational methods as part of their problem solving processes in engineering design. At the same time, this study also provides a framework for future studies using a larger sample size and specific themes to be explored further using interview or think-out-loud protocols.

\section{Acknowledgements}

This research was supported in part by the U.S. National Science Foundation under the award \#DMR 1305694. REG thanks the financial support from National Science Foundation CMMI 0856491. 


\section{References}

1 Lee, C. B., Jonassen, D. \& Teo, T. The role of model building in problem solving and conceptual change. Interactive Learning Environments 19, 247-265 (2011).

2 Stratford, S. J., Krajcik, J. \& Soloway, E. Secondary students' dynamic modeling processes: Analyzing, reasoning about, synthesizing, and testing models of stream ecosystems. Journal of Science Education and Technology 7, 215-234 (1998).

3 Smith, C., Snir, J. \& Grosslight, L. Using conceptual models to facilitate conceptual change: The case of weight-density differentiation. Cognition and Instruction 9, 221-283 (1992).

4 Hamilton, E., Lesh, R., Lester, F. \& Brilleslyper, M. Model-eliciting activities (MEAs) as a bridge between engineering education research and mathematics education research. Advances in Engineering Education 1, $1-25$ (2008).

$5 \quad$ Chi, M. T. H., Feltovich, P. J. \& Glaser, R. Categorization and representation of physics problems by experts and novices. Cognitive Science 5, 121-152 (1981).

$6 \quad$ Streveler, R. A., Litzinger, T. A., Miller, R. L. \& Steif, P. S. Learning conceptual knowledge in the engineering sciences: Overview and future research directions. Journal of Engineering Education 97, 279294 (2008).

7 De Jong, T. \& Van Joolingen, W. R. Scientific discovery learning with computer simulations of conceptual domains. Review of educational research 68, 179 (1998).

8 Magana, A. J., Brophy, S. P. \& Bodner, G. M. Instructors' Intended Learning Outcomes for Using Computational Simulations as Learning Tools. Journal of Engineering Education 101, 220-243 (2012).

9 Zawojewski, J. in Modeling Students' Mathematical Modeling Competencies (eds R Lesh, P Galbraith, C Haines, \& A Hurford) Ch. 20, 237-243 (Springer, 2010).

10 Conole, G. The role of mediating artifacts in learning design. Handbook of Research on Learning Design and Learning Objects: Issues, Applications, and Technologies 1, 188-208 (2009).

11 Nardi, B. A. Context and consciousness: activity theory and human-computer interaction. (The MIT Press, 1996).

12 Engeström, Y. Learning by expanding. An activity-theoretical approach to developmental research. (Helsinki, 1987).

13 Vygotsky, L. S. Mind in society: The development of higher psychological processes. (Harvard University Press, 1978).

14 Kaptelinin, V. in Context and consciousness: activity theory and human-computer interaction (ed B.A. Nardi) Ch. 5, (The MIT Press, 1996).

15 Cool, T., Bartol, A., Kasenga, M., Modi, K. \& García, R. E. Gibbs: Phase equilibria and symbolic computation of thermodynamic properties. Calphad 34, 393-404 (2010).

Bartol, A., García, E. R., Ely, D. R. \& Guyer, J. The Virtual Kinetics of Materials Laboratory, $<$ https://nanohub.org/resources/vkmllive $>$ (2012).

17 Magana, A. J., Brophy, S. P. \& Bodner, G. M. An Exploratory Study of Engineering and Science Students' Perceptions of nanoHUB. org Simulations. International Journal of Engineering Education 28, 1019 (2012). 2013, from https://nanohub.org/groups/mse597batterymodeling/wiki/MainPage. Polya, G. How to solve it: A new aspect of mathematical method. (Princeton University Press, 2008). Patton, M. Q. Qualitative evaluation and research methods. 3 edn, (Sage Publications, Inc, 2002). Jonassen, D. Toward a design theory of problem solving. Educational Technology Research and Development 48, 63-85 (2000). 165-196 (Lawrence Erlbaum Associates, 2000). 